\title{
DAILY AND SEASONAL VARIATION IN THE SPECTRAL COMPOSITION OF LIGHT EXPOSURE IN HUMANS
}

\author{
Helen C Thorne ${ }^{1}$, Kay KH Jones ${ }^{1}$, Stuart Peters ${ }^{2}$, Simon N Archer ${ }^{1}$, Derk-Jan Dijk ${ }^{1}$ \\ ${ }^{1}$ Surrey Sleep Research Centre, Faculty of Health and Medical Sciences, University of \\ Surrey, Guildford, Surrey, UK \\ ${ }^{2}$ Surrey Clinical Research Centre, Faculty of Health and Medical Science, University of \\ Surrey, Guildford, Surrey, UK
}

Corresponding author: Dr Helen Thorne, Surrey Sleep Research Centre, Faculty of Health and Medical Sciences, University of Surrey, Guildford, GU2 7XP, UK.

Email: Helen.Thorne@surrey.ac.uk, Tel: +44 1483682509. 
Keywords: melanopsin, blue light, circadian photoreception, seasons

\section{ABSTRACT}

Light is considered the most potent synchronizer of the human circadian system and exerts many other non-image forming effects, including those that affect brain function. These effects are mediated in part by intrinsically photosensitive retinal ganglion cells that express the photopigment melanopsin. The spectral sensitivity of melanopsin is greatest for blue light at approximately $480 \mathrm{~nm}$. At present, there is little information on how the spectral composition of light to which people are exposed varies over the 24 -h period and across seasons. Twenty two subjects, aged $22 \pm 4$ years (mean $\pm \mathrm{SD})$ participated during the winter months (Nov-Feb) and 12 subjects aged $25 \pm 3$ years, participated during the summer months (Apr-Aug). Subjects wore Actiwatch-RGB monitors, as well as Actiwatch-L monitors, for 7 consecutive days whilst living in England. These monitors measured activity, light-exposure in the red, green and blue spectral regions, in addition to broad-spectrum white light, with a two-minute resolution. Light exposure during the day was analyzed for the interval between 9:00 and 21:00 h. The time course of white light exposure significantly differed between seasons ( $p=$ 0.0022), with light exposure increasing in the morning hours, and declining in the afternoon hours, with a more prominent decline in the winter. Overall light exposure was significantly higher in summer compared to winter $(p=0.0002)$. Seasonal differences in the relative contribution of blue light exposure to overall light exposure were also observed $(p=0.0006)$, in particular during the evening hours. During the summer evenings (17:00-21:00 h), the relative contribution of blue light was significantly higher $(p<0.0001)(40.2 \pm 1.1 \%)$ than during winter evenings $(26.6 \pm 0.9 \%)$. The present data 
show that in addition to overall light exposure, the spectral composition of light exposure varies over the day and with season. 


\section{INTRODUCTION}

Light is not only essential for vision, but also modulates many aspects of behavior and physiology. These are referred to as non-image forming (NIF) responses and include classical effects such as phase shifting of sleep timing (Dijk et al., 1987) and circadian melatonin rhythms (Bojkowski et al., 1987; Broadway et al., 1987), as well as suppression of melatonin (Lewy et al., 1980; Zeitzer et al., 2000). These NIF responses extend, however, beyond circadian phase shifting and endocrine responses and include effects on alertness and performance and brain responses detected by either EEG (Badia et al., 1991; Cajochen et al., 1998; Phipps-Nelson et al., 2003), PET (Perrin et al., 2004) or fMRI (Vandewalle et al., 2006). The photopigment melanopsin, located in the human inner retina (Provencio et al., 2000), has been shown to play a major role in mediating these responses to light. It has now been established that circadian photo-entrainment is mediated in part by intrinsically photosensitive retinal ganglion cells (ipRGC) that express this photopigment. The ipRGCs relay information to the master circadian clock in the suprachiasmatic nuclei ( $\mathrm{SCN})$ via the retinohypothalamic tract, and to other brain regions including the Ventro-Lateral Pre-Optic (VLPO) area. These wide ranging projections provide a neuroanatomical basis for the variety of NIF responses to light (Hattar et al., 2002; Gooley et al., 2003).

The spectral sensitivity of melanopsin is known to be greatest for blue light at approximately $480 \mathrm{~nm}$ (Berson et al., 2002), which is in accordance with the previously observed short-wavelength sensitivity of melatonin suppression (Brainard et al., 2001; Thapan et al., 2001). Many subsequent studies have investigated the effectiveness of monochromatic blue light with respect to a number of NIF responses, including phase 
shifting (Warman et al., 2003), alertness, performance and EEG detected changes in brain function during the evening hours (Cajochen et al., 2005; Lockley et al., 2006) and during the biological night (Lockley et al., 2006), as well as fMRI studies of brain function during the daytime (Vandewalle et al., 2007a; Vandewalle et al., 2007b). The latter results demonstrated that monochromatic light can affect brain responses to cognitive tasks almost instantaneously and suggest that these effects are mediated by a melanopsinbased photoreceptor system.

These laboratory based studies demonstrating the superiority of blue monochromatic light in eliciting a variety of NIF responses have also led to field studies investigating the effects of 'blue-enriched' light compared to broad-spectrum white light. These studies include a small study on the effects of blue enriched light on subjective sleep measures and circadian phase in Antarctica (Francis et al., 2008), as well as a large scale study of the effects of blue enriched white light on self-reported performance, alertness and subjective sleep quality in office workers studied in the UK during the winter months (Viola et al., 2008). The latter study demonstrated positive effects of blue enriched light on self-reported alertness and performance as well as sleep quality whereas the former study demonstrated positive effects on sleep quality only.

Previous studies have demonstrated that light exposure varies with time of day, with light exposure rapidly rising in the morning hours, and then declining in the later hours of the afternoon (Graw et al., 1999; Rufiange et al., 2003; Goulet et al., 2007). Also, light exposure varies across the seasons, with light exposure being greatest in the summer months in the Northern hemisphere (Eastman, 1990; Park et al., 2007). This seasonal variation in light exposure has been hypothesized to contribute to conditions 
such as Seasonal Affective Disorder (SAD), which occurs during the winter months, with remission in the summer months (Rosenthal et al., 1984; Golden et al., 2005).

At present there is, however, little information on the time course of the spectral composition of light to which people are exposed over the 24-h period and across seasons. In fact, a recent comprehensive review of the available data on light exposure by Dumont and Beaulieu (2007) did not contain any information on the spectral composition of light exposure.

England's latitude and climate is such that day length varies considerably across seasons, and more time is spent indoors during the winter than during summer. Furthermore, artificial light, in general, is of lower intensity (Figuerio et al., 2006) and contains less blue light than natural light. Therefore, we hypothesized that 1) the time course of light exposure varies throughout the day and also with season, 2) light exposure in summer is significantly greater than during the winter, 3) the relative contribution of blue light in summer is greater than that during winter.

\section{METHODS}

\section{Subjects}

A total of thirty-four subjects (14 male) aged 18-29 years participated in the study. Twenty-two subjects with mean age $22.5 \pm 3.9$ years (mean \pm SD), body mass index (BMI) $22.0 \pm 2.3 \mathrm{~kg} / \mathrm{m}^{2}$, participated during the winter months (November-February, 2007). Twelve subjects with mean age $25.4 \pm 3.1$ years, BMI $22.1 \pm 2.9 \mathrm{~kg} / \mathrm{m}^{2}$, participated in the summer months (April-August, 2007-2008). Subjects completed the Horne Östberg (HÖ) questionnaire (Horne \& Östberg, 1976) and the Pittsburgh Sleep 
Quality Index (PSQI) (Buysse et al., 1989). The University of Surrey Ethics Committee approved the study protocol, subjects gave written consent, and all procedures were conducted in accordance with the Declaration of Helsinki and conformed to international ethical standards (Portaluppi et al., 2008).

\section{Study design}

Subjects wore Actiwatch RGB (Version 1.003) monitors (Cambridge Neurotechnology Ltd, Cambridge, UK) for 7 consecutive days in either summer or winter. The RGB actiwatch is a small, color-sensing device that combines three photodiodes with dye-based red, green, blue (RGB) filters, and a current-to-frequency converter circuit on a single chip. It reports in arbitrary units, as analogue frequency, the amount of short-wave (blue, 400-580 $\mathrm{nm}$ (peak sensitivity $470 \mathrm{~nm}$ )), medium-wave (green, 500-650 nm (peak sensitivity $565 \mathrm{~nm}$ )), long-wave (red, 620-720 nm (peak sensitivity $640 \mathrm{~nm}$ )) and broad band (white) light. The relative spectral responsivities, normalized to the white-light sensor at $540 \mathrm{~nm}$, are approximately $0.7,0.8$, and $0.5 \mathrm{for}$ the blue, green and red sensors, respectively. The data were stored with a two minute resolution and were recorded for 7 consecutive days while the subjects, mainly university students, apart from 3 subjects ( 1 outdoor worker and 2 indoor workers) went about their usual activities. In addition to these monitors, the subjects wore Actiwatch-L monitors (Cambridge Neurotechnology Ltd, Cambridge, UK), which measured broad band white light and activity, also with a two minute resolution. Both actiwatches were worn on the non-dominant wrist. Subjects were instructed only to remove the actiwatches during 
showering/bathing. These short time periods were excluded from the analysis along with rare periods of light exposure during the day where the actiwatch light readings were zero. This was based on the assumption that during these periods the actiwatch was being covered by clothing. Subjects also completed daily sleep diaries to verify the timing of sleep and wakefulness. In these diaries, sleep onset, sleep offset, sleep latency, sleep duration and the number and duration of night awakenings were determined.

The RGB Actiwatches were used for the analysis of red, green and blue light exposure, and the Actiwatch-L's were used for the data analysis of broad band white light exposure and activity. The seven days of data for each individual subject were averaged per hourly bin (1-24 h).

\section{Statistics}

All statistical analyses were performed with SAS version 9.1 (SAS Institute, Cary, North Carolina, USA). The absolute and relative light exposure for each of the 3 different colors (red, green and blue) and white light exposure were subjected individually to general linear modeling with season (winter or summer) as a fixed effect factor and time (hourly time points from 9:00-21:00 h) as a repeated measurement. Correlations between the observations obtained from the same subject were accounted for with an unstructured variance covariance matrix. A season-by-time interaction was also modeled. Variance components were estimated using restricted maximum likelihood. Least squares estimates from this statistical model were used to compare the effects of season and time on light exposure. Presented values are mean \pm SEM unless otherwise stated. 


\section{RESULTS}

No significant differences were observed between the subjects studied in the summer and winter months in terms of age, BMI, PSQI score $(3.4 \pm 2.1$ and $4.2 \pm 1.6)$ and HÖ score $(53 \pm 4$ and $53 \pm 2)$ for summer and winter respectively. No significant differences where observed in the activity levels $(17,393 \pm 627 \mathrm{cpm}$ and 19,679 \pm 539 cpm), mean sleep onset (23:46 $\pm 0: 16$ mins and 00:27 $\pm 0: 10$ mins $)$, mean sleep offset times (07:34 \pm 0:09 mins and 08:15 \pm 0:09 mins) and sleep duration (7:48 \pm 0:12 mins and 7:48 \pm 0:09 mins) between summer and winter respectively.

\section{Overall broad band white light exposure}

Light exposure during the day was analyzed for the period between 9:00-21:00 $\mathrm{h}$ because all subjects were awake during these times (See Fig 1). White light exposure increased throughout the morning hours, and peaked at approximately 11:00 $\mathrm{h}(1072 \pm$ 319 lux $)$ in the summer and 10:00 h $(522 \pm 188$ lux $)$ in the winter. White light exposure declined in the afternoon, with this decline being more prominent in winter compared to summer. Accordingly, a significant interaction between season-by-time was observed for white light $(p=0.0022)$. Comparing the overall light exposure revealed that in the summer subjects were exposed to significantly more light (586.8 \pm 89.4 lux) compared to those studied in winter $(209.9 \pm 43.0$ lux $)(p=0.0002)$. 


\section{Figure 1 about here}

\section{Spectral composition of light exposure}

Absolute values of red, green and blue light exposure (Table 1, Figure 2) were calculated separately for summer and winter months. These absolute values were then used to calculate the relative (\%) contribution of the three wavelengths, such that the sum of red, green and blue light equaled $100 \%$.

\section{Table 1 about here}

\section{Figure 2 about here}

Significant differences between seasons were observed for all measured variables (absolute red, green and blue light exposure, relative red, green and blue light exposure). In accordance with the observed lower exposure to white light, exposure to red, green and blue during the 9:00 to 21:00 h interval were all reduced during the winter compared to the summer $(p<0.01)$. Thus, during the winter exposure to blue light was significantly lower $(p=0.0006)$ than during the summer. A significant interaction between time-byseason was observed for all 3 colors $(p=0.0099,0.0014$ and 0.0006$)$ for red, green and blue respectively. 
Analysis of the time course of light exposure during the day revealed that the seasonal effect was particularly pronounced in the evening hours (17:00-21:00 h). During 17:00-21:00 $\mathrm{h}$, the relative contribution of blue light to the overall light exposure in subjects studied in the summer was significantly higher $(p<0.0001)(40.2 \pm 1.1 \%)$ than the relative contribution of blue light in subjects studied in winter $(26.6 \pm 0.9 \%)$. During this interval, the relative contribution of both red and green light was higher during the winter compared to summer, $(p=0.0001$ and 0.0104 respectively $)$.

Comparison of the relative contribution of red, green and blue light for all hourly intervals between 9:00-21:00 h showed that seasonal differences were also present during the daytime hours. Thus, in the late afternoon and early evening the relative contribution of blue light was significantly lower, and the relative contribution of red and green light was significantly higher, when comparing light exposure during the winter and summer ( $p<0.05$; Figure 3). In fact, even during the morning hours, this effect of season could be observed, although not all of the contrasts were statistically significant

\section{Figure 3 about here}

\section{DISCUSSION}

The data show that both total light exposure and its spectral composition vary across the day and between summer and winter. Our finding that light exposure is highest in the morning hours is at variance with two Canadian studies and one Swiss study which also recorded light exposure with wrist-worn monitors. Guillemette et al. (1998) reported 
light exposure from a mixture of students and unemployed subjects to be highest between 12:00-16:00 $\mathrm{h}$ for both summer and winter months, and Goulet et al. (2007) reported peak exposures at 14:00 $\mathrm{h}$ during the summer months. Graw et al. (1999), reported light exposure in a Swiss population in both the summer and winter being highest at 15:00 $\mathrm{h}$. Our findings are, however, similar to Rufiange et al. (2003), whose study was conducted throughout the year. In that study, light exposure was reported to be highest in the morning, with peak times located at 10:00 $\mathrm{h}$ and 12:00 $\mathrm{h}$ for Canadian outdoor workers and indoor workers, respectively, with outdoor workers receiving more light exposure than indoor workers. These observed differences in the time course may be attributed to latitude and climate variations. The subjects studied in our study were mainly students, and so may not be directly comparable to daytime workers who typically rise earlier and receive light exposure on their commute to and from work, and possibly during their lunch break.

In this study, different subjects and group sizes were compared in the winter to the summer. Therefore, it is possible that subject specific differences in behavior and life style could have contributed to the differences of light exposure profiles observed between the two seasons. Nevertheless, the explanation that the differences are simply related to season remains the most parsimonious explanation.

Our observation that during the summer, light exposure was significantly higher compared to winter is not surprising and is in accordance with previous studies of seasonal variation in light exposure (Guillemette et al., 1998; Hébert et al., 1998; Higuchi et al., 2007). It cannot be excluded that the lower light levels observed in this study in the winter may in part be due to subjects having covered their actiwatches with their sleeves 
or gloves, though this was hopefully minimized by deleting the raw light exposure levels that read as zero during the day.

A new observation of the present study is that the relative contribution of blue light to overall light exposure varies with season such that is lower during the winter than summer, and in particular during the evening hours. This may reflect seasonal variation in cloud cover and the height of the sun, as well as the larger contribution of artificial light exposure during the winter.

Studies on exposure to white light have previously highlighted that differences in light exposure between adapting and non-adapting shift workers (Dumont et al., 2001), as well as between morning and evening types (Goulet et al., 2007), are primarily located in the evening hours. The present findings extend these observations on white light exposure to the spectral composition of light exposure during the evening and point to the potential importance of evening light exposure, rather than morning light. From Figure 2, it is clearly visible that in the summer subjects are exposed to twice as much blue light than in the winter. The timing of this blue light could indeed have some circadian effects; it is well known that bright light exposure in the evening will cause a phase delay of the circadian clock (Czeisler et al., 1989).

The contribution of artificial light to overall light exposure is very likely to have contributed to the large reduction in the relative contribution of blue light to overall light exposure during the winter evenings in particular. Most artificial light sources contain relatively little blue light, in part because the specifications for artificial light are based on visual requirements and do not take the spectral sensitivity of NIF responses into account (European Committee for Standardization, 2003). 
The role of blue and green light has been highlighted as fundamentally important in the treatment of SAD. Meta analyses indicate that wavelengths of short to medium, i.e. green, blue and yellow wavelengths of light, and full-spectrum light yield larger treatment effects in SAD than longer wavelengths such as red light (Lee et al., 1997). More recently, a study by Glickman et al. (2006) demonstrated that narrow-bandwidth blue light ( $\lambda \max 468 \mathrm{~nm})$ was more effective in the treatment of SAD compared to red light $(\lambda \max 654 \mathrm{~nm})$, though how this compares to normal white light was unfortunately not investigated.

\section{CONCLUSIONS}

The present data show that in addition to overall light exposure, the spectral composition of blue light varies with time of day and with season. Further investigation of these variations and the genetic variation in melanopsin (Roecklein et al. 2008) may contribute to our understanding of inter-individual and seasonal changes in entrainment and its disorders. The present data contribute to the rationale for investigating whether enriching artificial light with blue light, or other novel light therapies, may reduce the incidence of seasonal affective disorders and other seasonal sleep and circadian disorders. 


\section{Acknowledgements}

This research was supported by the Wellcome Trust $(069714 / \mathrm{Z} / 02 / \mathrm{Z})$ and the Biotechnology and Biological Sciences Research Council (BBSRC) (BSS/B/08523).

\section{Conflicts of interest}

This is not an industry sponsored study. DJD has received research support from, and has served as a consultant to Philips lighting. DJD and SNA are beneficiaries on a patent related to light by the University of Surrey.

\section{REFERENCES}

Badia P, Myers B, Boecker M, Culpepper J and Harsh JR. (1991). Bright light effects on body temperature, alertness, EEG and behavior. Physiol. Behav. 50:583-588.

Berson DM, Dunn FA and Takao M. (2002). Phototransduction by retinal ganglion cells that set the circadian clock. Science 295:1070-1073.

Bojkowski CJ, Arendt J, Shih MC and Markey SP. (1987). Melatonin secretion in humans assessed by measuring its metabolite, 6-sulphatoxymelatonin. Clin. Chem. 33:1343-1348.

Brainard GC, Hanifin JP, Greeson JM, Byrne B, Glickman G, Gerner E and Rollag MD. (2001). Action spectrum for melatonin regulation in humans: evidence for a novel circadian photoreceptor. J. Neurosci. 15:5088-5097. 
Broadway J, Arendt J and Folkard S. (1987). Bright light phase shifts the human melatonin rhythm during the Antarctic winter. Neurosci. Lett. 79:185-189.

Buysse DJ, Reynolds CF, Monk TH, Berman SR and Kupfer DJ. (1989). The Pittsburgh Sleep Quality Index: a new instrument for psychiatric practice and research. Psychiatry Res. 28:193-213.

Cajochen C, Kräuchi K, Danilenko KV and Wirz-Justice A. (1998). Evening administration of melatonin and bright light: interactions on the EEG during sleep and wakefulness. J. Sleep Res. 7:145-157.

Cajochen C, Münch M, Kobialka S, Kräuchi K, Steiner R, Oelhafen P, Orgül S and WirzJustice A. (2005). High sensitivity of human melatonin, alertness, thermoregulation, and heart rate to short wavelength light. J. Clin. Endocrinol. Metab. 90:1311-1316.

Czeisler CA, Kronauer RE, Allan JS, Duffy JF, Jewett ME, Brown EN and Ronda JM. (1989). Bright light induction of strong (type 0) resetting of the human circadian pacemaker. Science. 244:1328-1333.

Dijk DJ, Visscher CA, Bloem GM, Beersma DG and Daan S. (1987). Reduction of human sleep duration after bright light exposure in the morning. Neurosci. Lett. 73:181-186.

Dumont $\mathrm{M}$ and Beaulieu C. (2007). Light exposure in the natural environment: relevance to mood and sleep disorders. Sleep Med. Rev. 8:557-565.

Dumont M, Benhaberou-Brun D and Paquet J. (2001). Profile of 24-h Light Exposure and Circadian Phase of Melatonin Secretion in Night Workers. J. Biol. Rhythms 16:502-511.

Eastman CI. (1990). Natural summer and winter sunlight exposure patterns in seasonal affective disorder. Physiol. Behav. 48:611-616.

Figuerio MG, Rea MS and Bullough JD. (2006). Does architectural lighting contribute to breast cancer? J. Carcinog. 5:20.

Francis G, Bishop L, Luke C, Middleton B, Williams P and Arendt J. (2008). Sleep during the Antarctic winter: preliminary observations on changing the spectral composition of artificial light. J. Sleep Res. 17:354-360.

Glickman G, Byrne B, Pineda C, Hauck WW and Brainard GC. (2006). Light therapy for seasonal affective disorder with blue narrow-band light-emitting diodes (LEDs). Biol. Psychiatry 59:502-507. 
Golden RN, Gaynes BN, Ekstrom RD, Hamer RM, Jacobsen FM, Suppes T, Wisner KL and Nemeroff CB. (2005). The efficacy of light therapy in the treatment of mood disorders: a review and meta-analysis of the evidence. Am. J. Psychiatry 162:656662.

Gooley JJ, Lu J, Fischer D and Saper CB. (2003). A broad role for melanopsin in nonvisual photoreception. J. Neurosci. 23:7093-7106.

Goulet G, Mongrain V, Desrosiers C, Paquet J and Dumont M. (2007). Daily light exposure in morning-type and evening-type individuals. J. Biol. Rhythms 22:151158.

Graw P, Recker S, Sand L, Kräuchi K and Wirz-Justice A. (1999). Winter and summer outdoor light exposure in women with and without seasonal affective disorder. $J$. Affect. Disord. 56:163-169.

Guillemette J, Hebert M, Paquet J and Dumont M. (1998). Natural bright light exposure in the summer and winter in subjects with and without complaints of seasonal mood variations. Biol. Psychiatry 44:622.

Hattar S, Liao HW, Takao M, Berson DM, Yau KW and Tachibana N. (2002). Melanopsin-containing retinal ganglion cells: architecture, projections, and intrinsic photosensitivity. Science 295:1065-1070.

Hébert M, Dumont M and Paquet J. (1998). Seasonal and diurnal patterns of human illumination under natural conditions. Chronobiol. Int. 15:59-70.

Higuchi S, Motohashi Y, Ishibashi K and Maeda T. (2007). Less exposure to daily ambient light in winter increases sensitivity of melatonin to light suppression. Chronobiol. Int. 24:31-43.

Horne $\mathrm{J}$ and Östberg O. (1976). A self-assessment questionnaire to determine morningness-eveningness in human circadian rhythms. Int. J. Chronobiol. 4:97110.

Lee TM, Chan CC, Paterson JG, Janzen HL and Blashko CA. (1997). Spectral properties of phototherapy for seasonal affective disorder: a meta-analysis. Acta Psychiatr. Scand. 96:117-121.

Lewy AJ, Wehr TA, Goodwin FK, Newsome DA and Markey SP. (1980). Light suppresses melatonin secretion in humans. Science 210:1267-1269.

Lockley SW, Evans EE, Scheer FA, Brainard GC, Czeisler CA and Aeschbach D. (2006). Short-wavelength sensitivity for the direct effects of light on alertness, vigilance, and the waking electroencephalogram in humans. Sleep 29:161-168. 
Park DH, Kripke DF and Cole RJ. (2007). More prominent reactivity in mood than activity and sleep induced by differential light exposure due to seasonal and local differences. Chronobiol. Int. 24:905-920.

Perrin F, Peigneux P, Fuchs S, Verhaeghe S, Laureys S, Middleton B, Degueldre C, Del Fiore G, Vandewalle G, Balteau E, Poirrier R, Moreau V, Luxen A, Maquet P and Dijk DJ. (2004). Nonvisual responses to light exposure in the human brain during the circadian night. Curr. Biol. 26:1842-1846.

Phipps-Nelson J, Redman JR, Dijk DJ and Rajaratnam SM. (2003). Daytime exposure to bright light, as compared to dim light, decreases sleepiness and improves psychomotor vigilance performance. Sleep 26:695-700.

Portaluppi F, Touitou Y and Smolensky MH. (2008). Ethical and methodological standards for laboratory and medical biological rhythm research. Chronobiol. Int. 25:999-1016.

Provencio I, Rodriguez IR, Jiang G, Hayes WP, Moreira EF and Rollag MD. (2000). A novel human opsin in the inner retina. J. Neurosci. 20:600-605.

Roecklein KA, Rohan KJ, Duncan WC, Rollag MD, Rosenthal NE, Lipsky RH and Provencio I. (2009). A missense variant (P10L) of the melanopsin (OPN4) gene in seasonal affective disorder. J. Affect. Disord. 114:279-285.

Rosenthal NE, Sack DA, Gillin JC, Lewy AJ, Goodwin FK, Davenport Y, Mueller PS, Newsome DA and Wehr TA. (1984). Seasonal affective disorder. A description of the syndrome and preliminary findings with light therapy. Arch. Gen. Psychiatry 41:72-80.

Rufiange M, Lachapelle P and Dumont M. (2003). Effect of long-term light exposure on retinal and circadian light sensitivity of outdoor and indoor workers. Chronobio Int. 20:1159-1160.

Standardization ECf. (2003). Light and lighting: lighting of work places: indoor work places. Brussels: CEN European Standard:12464-12471.

Thapan K, Arendt J and Skene DJ. (2001). An action spectrum for melatonin suppression: evidence for a novel non-rod, non-cone photoreceptor system in humans. J. Physiol. 535:261-267.

Vandewalle G, Balteau E, Phillips C, Degueldre C, Moreau V, Sterpenich V, Albouy G, Darsaud A, Desseilles M, Dang-Vu TT, Peigneux P, Luxen A, Dijk DJ and Maquet P. (2006). Daytime light exposure dynamically enhances brain responses. Curr. Biol. 16:1616-1621. 
Vandewalle G, Gais S, Schabus M, Balteau E, Carrier J, Darsaud A, Sterpenich V, Albouy G, Dijk DJ and Maquet P. (2007a). Wavelength-dependent modulation of brain responses to a working memory task by daytime light exposure. Cereb. Cortex 17:2788-2795.

Vandewalle G, Schmidt C, Albouy G, Sterpenich V, Darsaud A, Rauchs G, Berken PY, Balteau E, Degueldre C, Luxen A, Maquet P and Dijk DJ. (2007b). Brain responses to violet, blue, and green monochromatic light exposures in humans: prominent role of blue light and the brainstem. PLOS ONE 2:e1247.

Viola AU, James LM, Schlangen L and Dijk DJ. (2008). Blue-enriched white light in the work place improves self-reported alertness, performance and sleep quality. Scand. J. Work Environ. Health 34:297-306.

Warman VL, Dijk DJ, Warman GR, Arendt J and Skene DJ. (2003). Phase advancing human circadian rhythms with short wavelength light. Neurosci. Lett. 342:37-40.

Zeitzer JM, Dijk DJ, Kronauer R, Brown E and Czeisler C. (2000). Sensitivity of the human circadian pacemaker to nocturnal light: melatonin phase resetting and suppression. J. Physiol. 526:695-702. 
Table 1

\begin{tabular}{|c|c|c|c|}
\hline Average Light exposure 9.00-21.00 h & Summer (N=12) & Winter (N=22) & Significance \\
\hline Red light exposure (arbitrary units) & $3762 \pm 673$ & $1174 \pm 293$ & $p=0.0008$ \\
\hline Green light exposure (arbitrary units) & $7293 \pm 1198$ & $2200 \pm 504$ & $p<0.0001$ \\
\hline Blue light exposure (arbitrary units) & $7887 \pm 1324$ & $2179 \pm 549$ & $p<0.0001$ \\
\hline Relative contribution of red light (\%) & $19.4 \pm 0.3$ & $21.5 \pm 0.5$ & $p<0.0001$ \\
\hline Relative contribution of green light (\%) & $39.4 \pm 0.2$ & $41.1 \pm 0.6$ & $p=0.0104$ \\
\hline Relative contribution of blue light (\%) & $41.3 \pm 0.5$ & $37.4 \pm 1.0$ & $p<0.0001$ \\
\hline
\end{tabular}

Figure 1 
a)
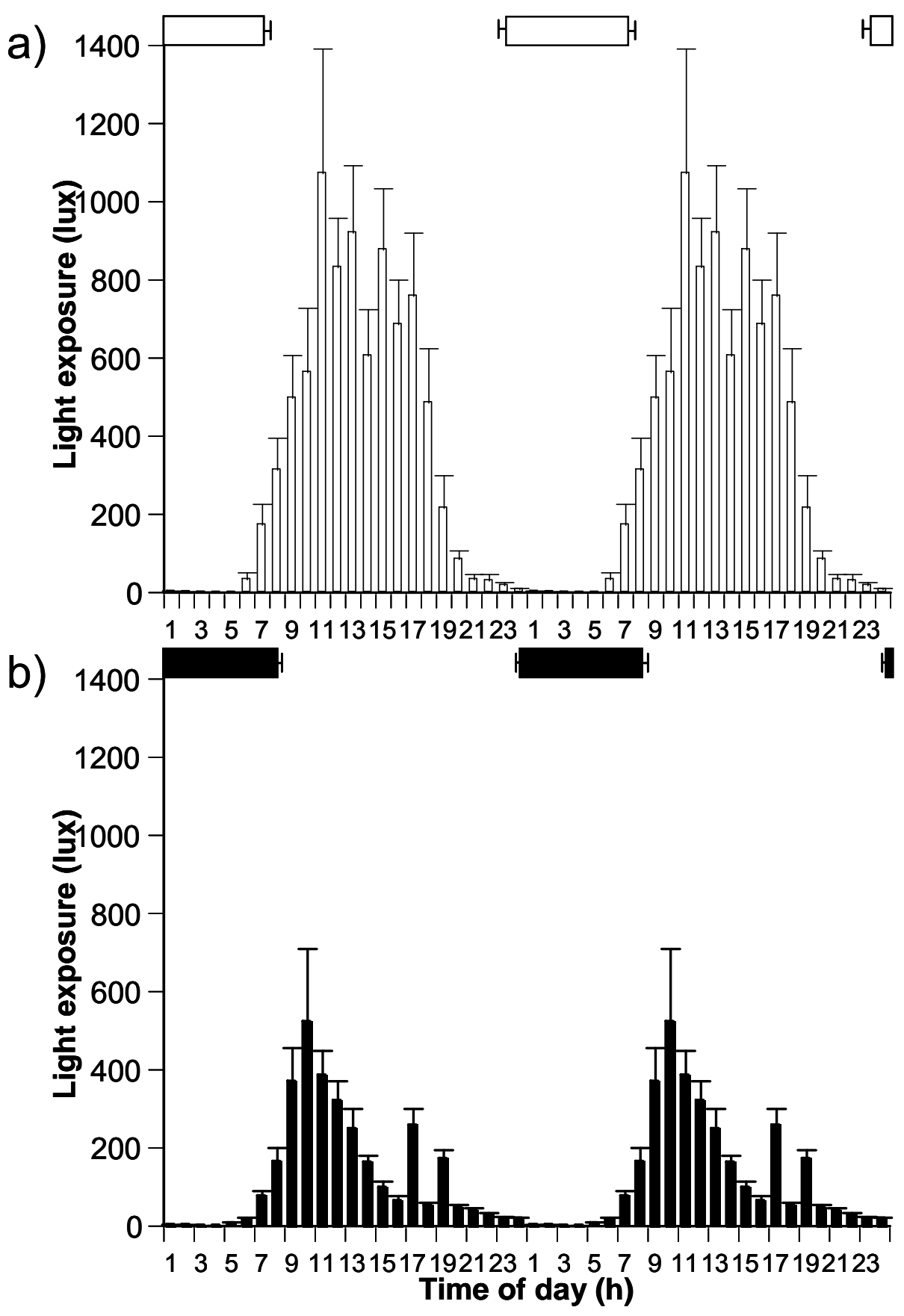

Figure 2 

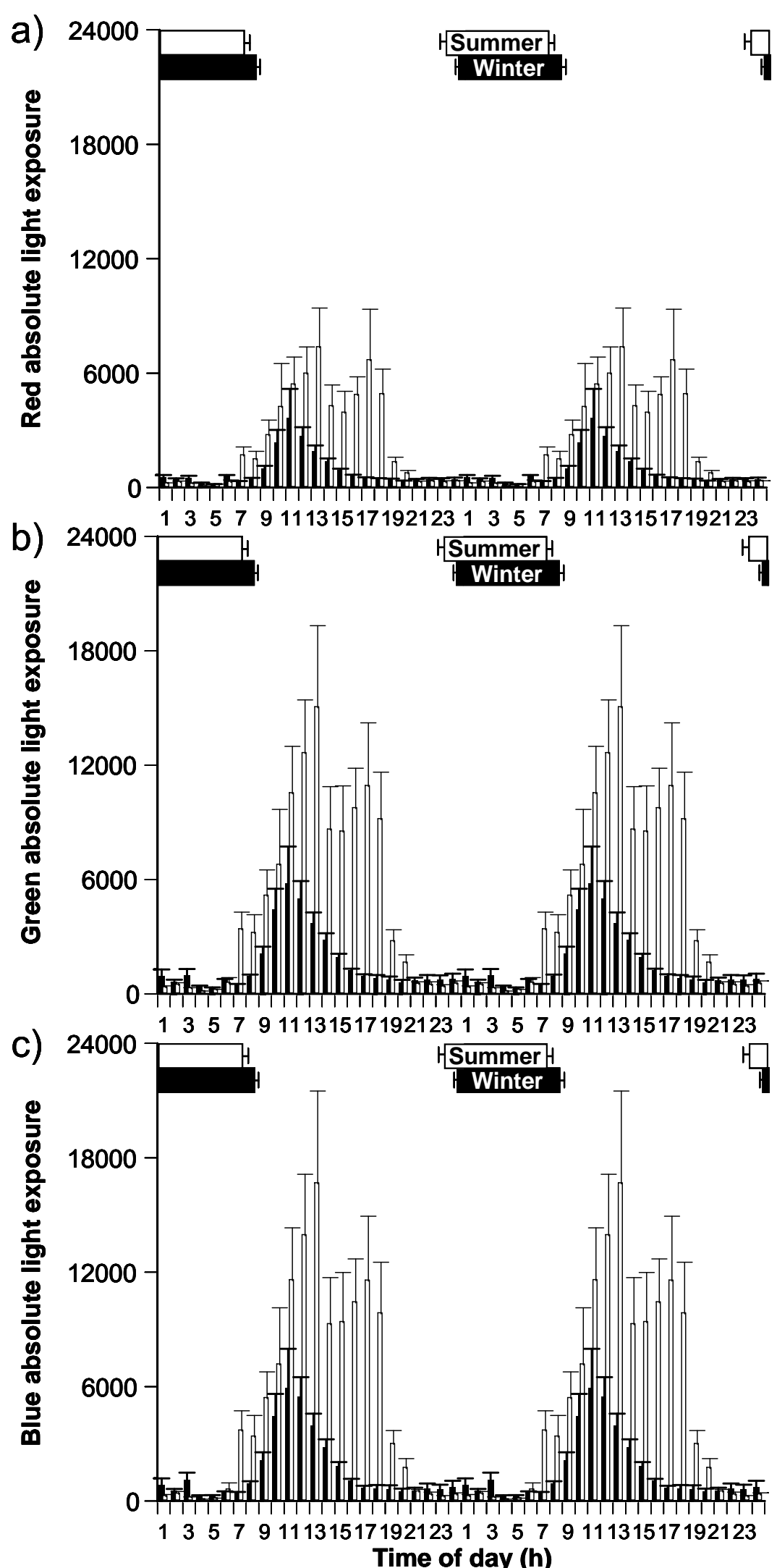

Time of day (h) 
Figure 3 
a) $30 \frac{\text { Summer }}{\text { Winter }}$
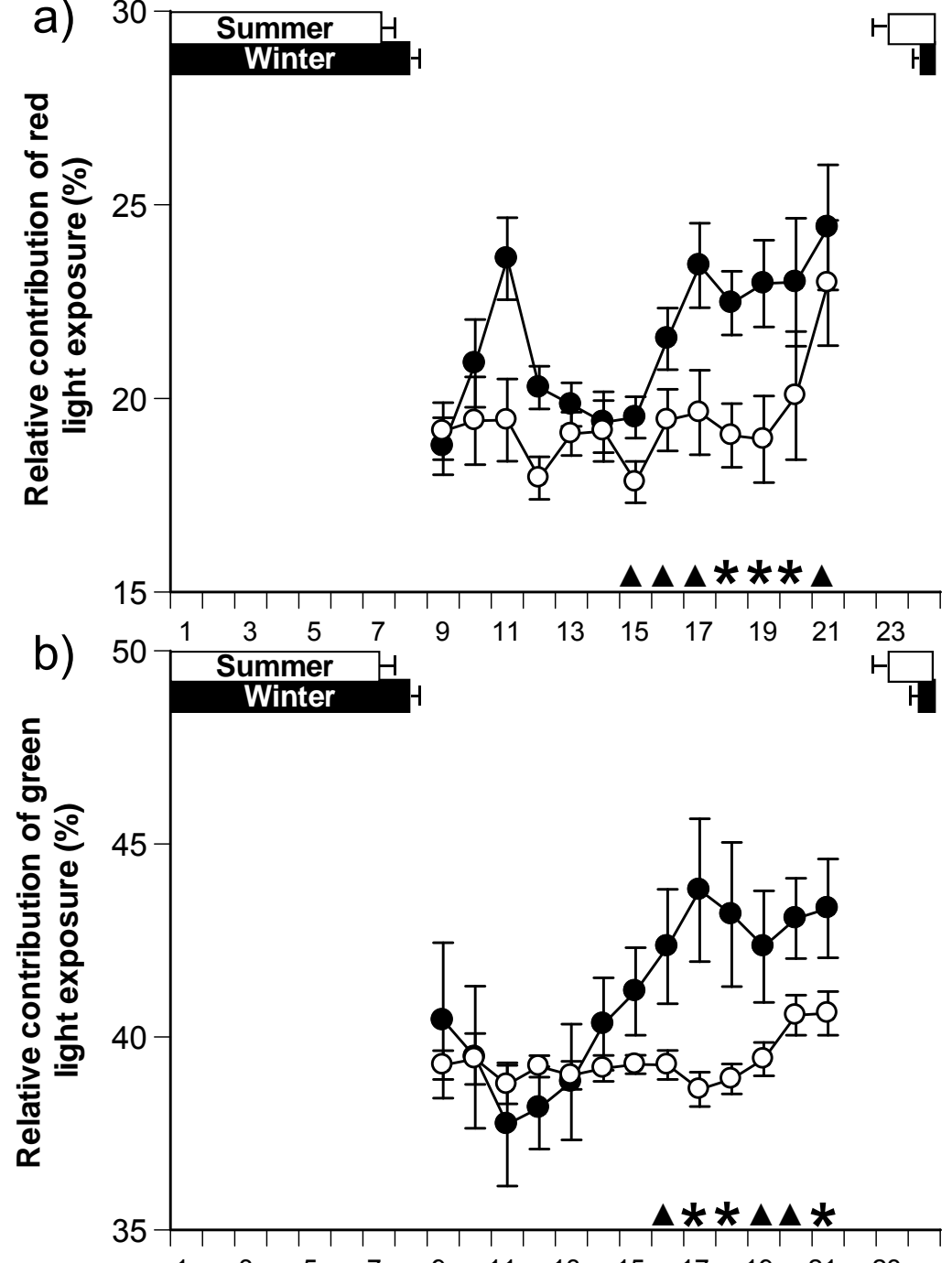

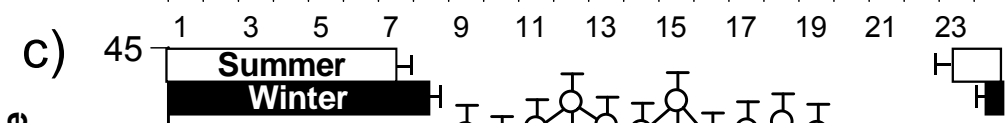

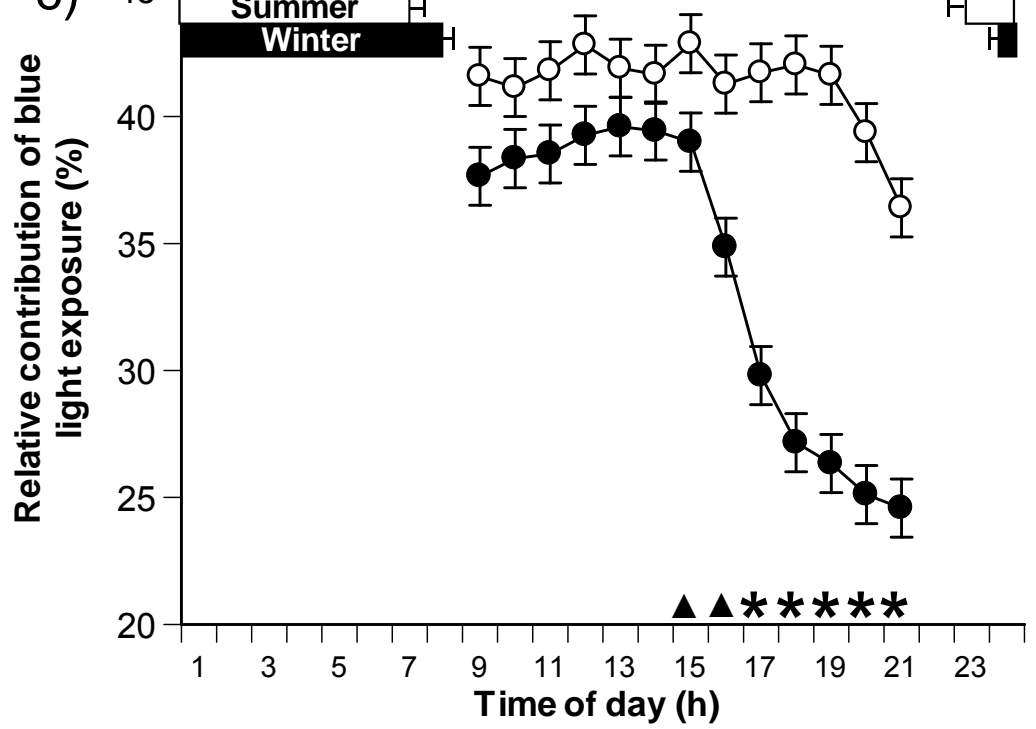


Table 1: Average ( \pm SEM) exposure to red, green and blue light between 9:00-21:00 $\mathrm{h}$ during summer and winter.

Figure 1: Average ( \pm SEM) 24-h light exposure (lux $)$ in a) summer $(\mathrm{N}=12)$ and b) winter $(\mathrm{N}=22)$. Data are double plotted. Horizontal bars on top of graph indicate the timing of sleep periods ( \pm SEM).

Figure 2: 24-h time course of light exposure. Mean ( \pm SEM) absolute values of (a) absolute red light exposure, (b) absolute green light exposure, (c) absolute blue light exposure for summer $(\mathrm{N}=12)$ (white bars) and winter $(\mathrm{N}=22)$ (black bars). Horizontal bars indicate the timing of sleep episodes $( \pm$ SEM).

Figure 3: Mean ( \pm SEM) relative contribution of (a) $\%$ red light exposure (b) $\%$ green light exposure (c) \% blue light to overall light exposure between 9:00 $\mathrm{h}$ and 21:00 $\mathrm{h}$ during summer $(\mathrm{N}=12)(\mathrm{O})$ and winter $(\mathrm{N}=22)(\bullet), \boldsymbol{\Delta} p \leq 0.05 * p \leq 0.0001$. Horizontal bars indicate the timing of sleep episodes ( \pm SEM). 